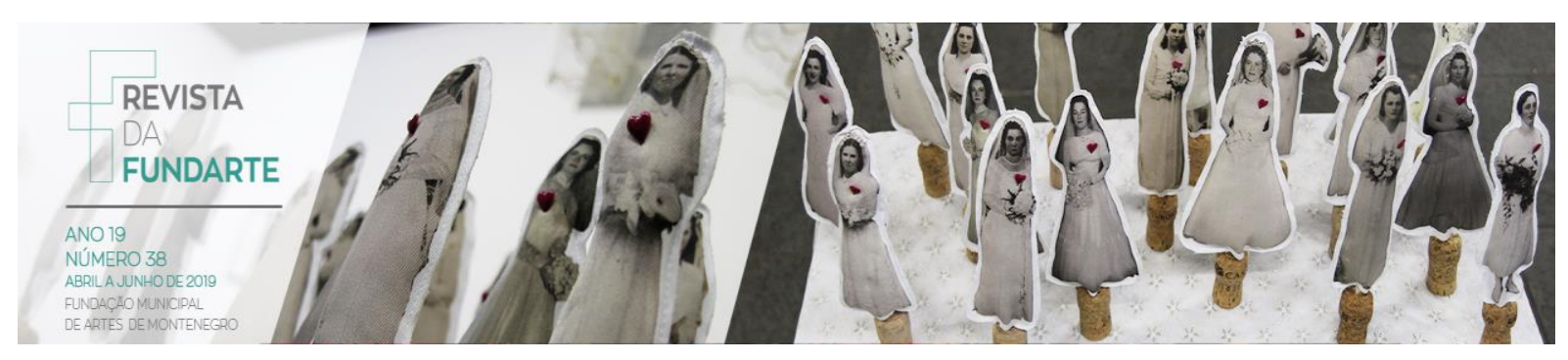

\title{
CORPOS CÊNICOS GORDOS EM UMA SOCIEDADE EXCLUDENTE
}

Tiago Martinelli Nogueira ${ }^{1}$

Resumo: Este ensaio apresenta reflexões sobre os corpos cênicos gordos e como a sociedade artística gera estereótipos sobre eles. Os corpos cênicos padrões são exigidos por toda essa sociedade que ainda preza por esses corpos. Penetrar nessa bolha de padrões estéticos tem sido o foco de muitos grupos e coletivos de atores e atrizes. Coloco minhas percepções como estudante de licenciatura em teatro e problematizo com algumas citações de Henri Bergson e Michel Foucault sobre o lugar que esse corpo cênico ocupa nesta sociedade que tem outros perfis de composição corporal.

Palavras-chave: Corpos cênicos; Artes cênicas; Composição corporal.

\section{FATAL CORPS IN AN EXCLUDING SOCIETY}

Abstract: This essay presents reflections on the fat scenic bodies and how the artistic society generates stereotypes about them. The standard scenic bodies are demanded by this whole society that still treasures these bodies. Penetrating this bubble of aesthetic standards has been the focus of many groups and collectives of actors and actresses. I put my perceptions as a student of degree in theater and problematizo with some quotations of Henri Bergson and Michel Foucault on the place that this scenic body occupies in that society that has other profiles of corporal composition.

Keywords: Scenic bodies; Performing Arts; Body composition.

Neste texto de caráter ensaístico coloco em escrita minha pesquisa sobre corpos cênicos gordos. Sempre fui gordo e somente após a entrada na universidade, comecei a observar algumas questões sobre o ensino de teatro tradicional, o qual não leva em conta os corpos "não ideais". Diante de tal constatação, comecei a fazer uma maior análise sobre onde se encaixam atores cênicos gordos e onde eu me encaixaria nesse contexto, a partir de conceitos de autores como Michel Foucault, Henri Bergson e Paola Altheia.

O teatro exige a presença de corpos, mas proponho repensar a concepção de corpos que temos atualmente. Em uma sociedade que impõe corpos magros e exclui os que não entram nesse padrão, onde se encaixam os atores com corpos

\footnotetext{
1 Graduando em Teatro: Licenciatura pela Universidade Estadual do Rio Grande do Sul/UERGS. Foi colaborador do Grupo Flume: Arte e Educação. Foi bolsista no programa institucional de iniciação à Docência/PIBID. Ator do Grupo ATRITO de Porto alegre/RS. Integrante do coletivo de coordenadores do Espaço Comunitário Vale do Caí: Lugar de arte e cultura.
}

NOGUEIRA, Tiago Martinelli. Corpos cênicos gordos em uma sociedade excludente. Revista da FUNDARTE, Montenegro, p.212-218, ano 19, no 38, abril/junho de 2019.

Disponível em: http://.seer.fundarte.rs.gov.br/index.php/RevistadaFundarte/index> 28 de junho de 2019. 


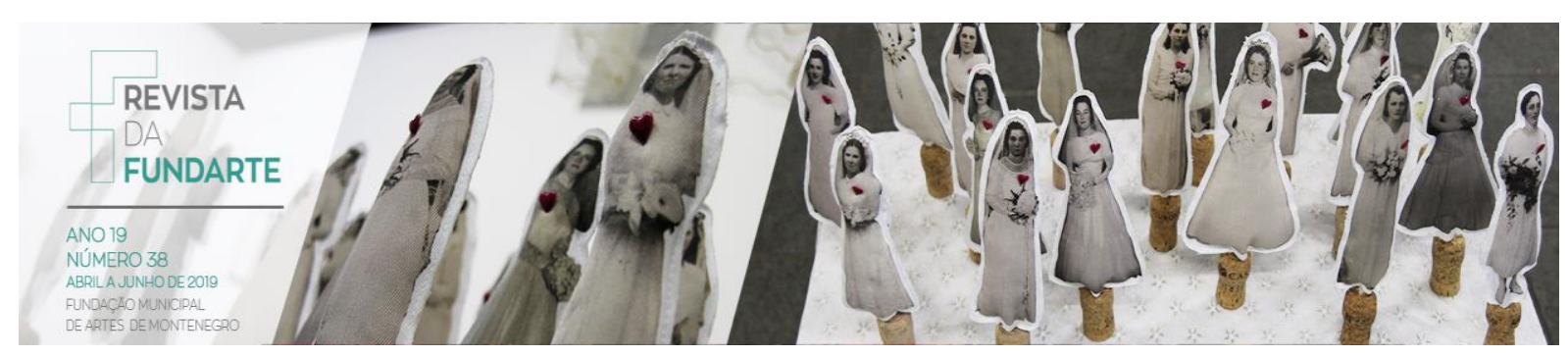

gordos nesse sistema excludente? $\mathrm{E}$ de que forma resistem a essa cadeia que os torna atores secundários? Bergson (2006, p.11) contribui dizendo que:

[...] meu corpo é, portanto, no conjunto do mundo material, uma imagem que atua como outras imagens, recebendo e devolvendo movimento, com a única diferença, talvez, de que meu corpo parece escolher [...]. ${ }^{2}$

Em uma sociedade onde a figura magra é tida como padrão de beleza, a população reproduz essa figura como verdade e acaba excluindo corpos que não estão dentro desse padrão, gerando o preconceito da gordofobia. Todos os questionamentos trazidos aqui suscitaram a presente análise, que começa no curso de Graduação em Teatro: Licenciatura na UERGS.

Quando o ano letivo começou, vi que na minha turma haviam corpos fora dos padrões impostos pela sociedade. A partir desse momento, comecei a observar que o meu corpo era um corpo fora do padrão, era um corpo obeso, e tinha que ser político também. Comecei, então, uma pesquisa, a partir de uma disciplina eletiva oferecida no curso de Graduação em Artes Visuais, a disciplina de tridimensional III, na qual comecei a pesquisar artigos, textos e fotos de corpos cênicos gordos ativos. Nessa pesquisa me deparei com o texto de Taynara Rocha, Fátima Lima e Steepahn Arnulf, a qual traz um título bem peculiar (Ressignificando as banhas) e relata que:

[...] Percebi que artistas gordos/as ocupam no cinema sempre os mesmos papéis: que comem demais, com autoestima deformada, que nunca se relaciona afetivamente, nunca atua o personagem principal $[\ldots]^{3}$

Dessa forma, percebe-se que gordofobia já vem de muito tempo, e a gula é considerada pela igreja católica como um dos sete pecados capitais, sendo que quem é gordo demonstra fracasso moral. A indústria farmacêutica lança produtos emagrecedores todos os anos, prometendo milagres e, juntamente, com essas promessas, aparecem as imagens nas campanhas publicitárias de pessoas com

\footnotetext{
${ }^{2}$ BERGSON, Henri. Matéria e memória, 2006, p.11.

${ }^{3}$ ROCHA, Taynara. LIMA, Fátima. ARNULF, Stephan. Ressignificando as banhas, 2018, p.1.
} 


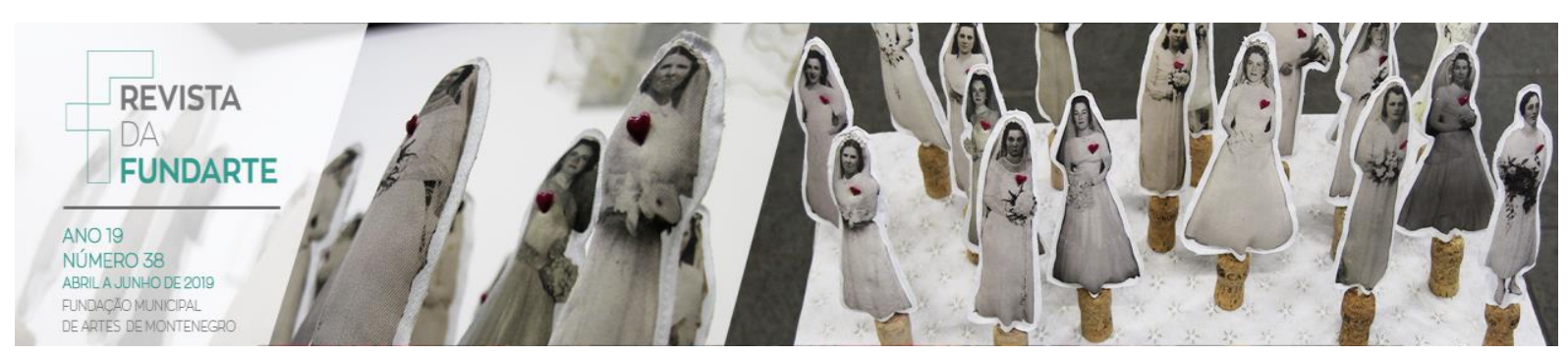

corpos gordos em situações que as evidenciam como incapazes, limitadas, preguiçosas e sem nenhuma libido. Esses dados encontram-se em blogs e em outros meios informais, como o da Paola Atheia, nutricionista e criadora do blog “ Não sou Exposição".

Estamos tentando há centenas de anos encontrar a solução da corpulência, mas nunca conseguimos. A partir do momento em que as primeiras relações entre problemas de saúde e gordura corporal começaram a ser publicadas, o gordo passou a responder por tripla acusação: falta de formosura, falta de retidão de espírito e falta de capacidade para gerenciar a própria saúde ${ }^{4}$

O índice de massa corporal (I.M.C.) é o que define cientificamente se tu és gordo ou não. Muito mais do que isso, o I.M.C, criado em 1832 pelo matemático Adolphe Quetelet, serve de guia para pesquisas sobre alimentação em todo o mundo. O grande problema desse índice é que ele não pode mensurar a alimentação ou os hábitos alimentares de cada corpo. Quem sempre esteve em luta com a balança, passava por momentos constrangedores, como ir ao médico, ou em aulas de Educação Física na escola, lugares onde eram feitas essa verificação nos alunos. Essas lembranças começaram a vir à tona no momento em que me vi em uma sala de aula da faculdade e eu era o único corpo gordo em cena.

Depois disso, a pesquisa sobre corpos gordos em cena começou a me chamar mais atenção e, ao mesmo tempo, me deixava ansioso e com receio de continuar o curso, pois não me via fazendo somente papéis cômicos, ou papéis que somente poderiam mostrar que o corpo gordo era um corpo, cuja a alma era de uma pessoa preguiçosa, ou então que não pudesse despertar a libido no público geral.

A criação de personagens, tanto para cinema quanto para televisão, tem um estereótipo para os corpos gordos que acaba influenciando novos corpos a terem hábitos alimentares e físicos relacionados a gordura. De acordo com a pesquisa do The Thelegraph, personagens gordos com hábitos de comer, fazem com que as crianças comam mais e pior, a qual afirma:

\footnotetext{
${ }^{4}$ ALTHEIA, Paola. Nutricionista e criadora do Blog Não Sou Exposição. 2017, p. 1.
} 


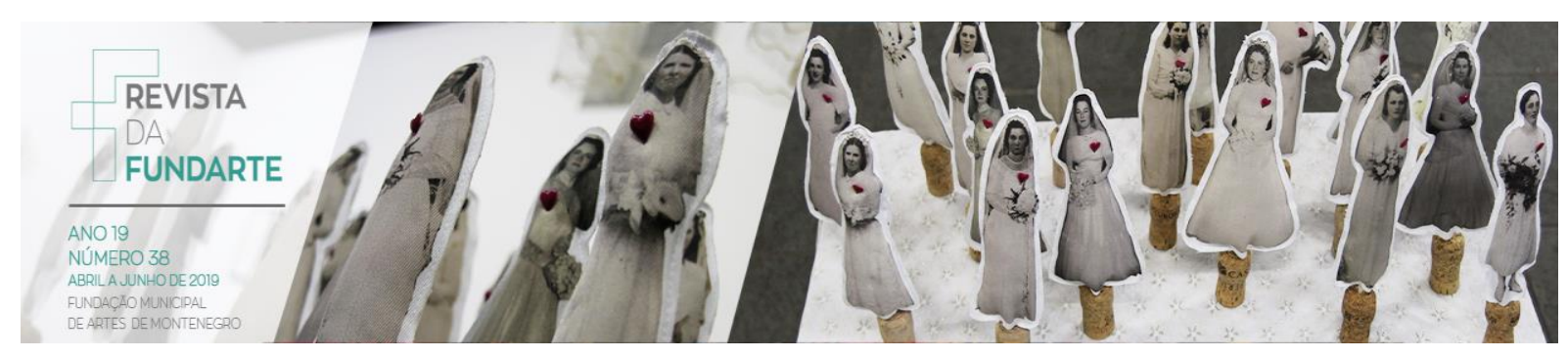

[...] pesquisadores norte-americanos constataram que as crianças que assistiam a personagens com excesso de peso (tanto na televisão como em histórias em quadrinhos) apresentaram uma maior tendência para alimentos não saudáveis quando recorriam àquilo que aprendiam com os desenhos animados. Além disso, tendem a comer duas vezes mais[...]. ${ }^{5}$

Desse modo, ressalto que os estereótipos criados por escritores e diretores tem tido sempre o mesmo perfil para corpos gordos: sem vontade de trabalhar, preguiçoso, desprovido de inteligência, sem preocupação com higiene, o que acaba influenciando quem assiste. Felizmente, no teatro, parece que esta problemática começa a avançar, uma vez que os corpos gordos têm tido maior visibilidade pelo trabalho de muitos grupos que têm observado esse estigma social do gordo e acreditado que somente a luz bem forte nesse assunto é capaz de elucidar questões e afastar o preconceito, conforme apontado pelas preparadoras corporais da peça Banhado,

[...] é importante falar sobre gordofobia e trazer luz a esse problema social para quebrar estigmas contra gordos. Dizem que gordo é fedido, preguiçoso, vagabundo e uma pessoa doente $[\ldots]^{6}$

$\mathrm{Na}$ peça Banhado, eles tratam sobre questões que Gabriel, ator do espetáculo, passa todos os dias ao enfrentar a roleta do ônibus, sentar em cadeiras plásticas, tudo com luz bem forte nessas questões. Música, teatro, dança, são todos os incrementos do espetáculo, o qual foi concebido depois de dois anos de pesquisa do grupo Petrichor.

[...] Meu corpo é o lugar ao qual estou condenado. Penso, afinal de contas, que é contra ele e como que para eclipsá-lo que criamos todas essas utopias. O prestígio da utopia, a beleza, o encanto da utopia, a que eles se devem? A utopia é um lugar fora de todos os lugares, mas é um lugar onde eu terei um corpo desencarnado, um corpo que será belo, puro, transparente, luminoso, célere, colossal em seu poder, infinito em sua duração, ágil, invisível, protegido, transfigurado; e pode muito bem ser que a utopia primeira, aquela mais inextirpável no coração dos homens, é precisamente a utopia de um corpo incorpóreo[... $]^{7}$

\footnotetext{
5 THE THELEGRAPH, Journal of Consumer Psychology. 2018, p.4.

${ }^{6}$ ELVIRA, Thais. Preparadora corporal da peça Banhado do Grupo Petrichor. 2017, p.1.

${ }^{7}$ FOUCAULT, Michel. A corpo utópico. 1966 p.36.
} 


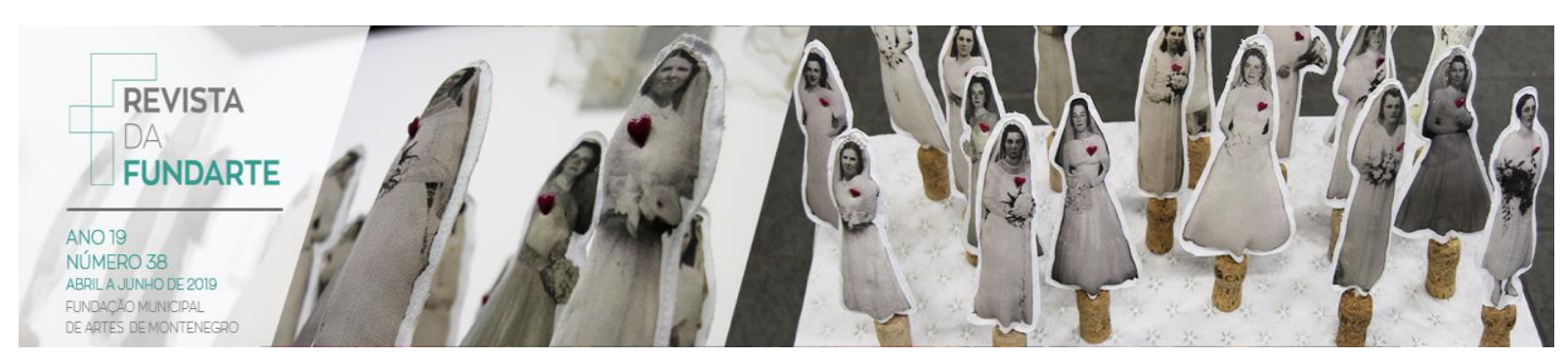

Foucault cita o corpo incorpóreo, que segundo ele é utópico, cujo corpo ao qual pertencemos é uma condenação, para o qual criamos utopias, que adotamos para esconder esse corpo gordo. Maquiagem, roupas nas cores pretas, cintas, óculos e tudo mais, os quais são usados para maquiar um corpo que não é aceito na sociedade, entretanto o corpo gordo é ágil e pode interagir com a cena, na mesma proporção em que um corpo magro pode interagir. As peças teatrais podem ser de inúmeras naturezas: circense, dramática, musical, infantil, etc. Delimitar a atuação de um corpo gordo em cena é dizer a esse corpo que ele não pode desenvolver esse tipo de trabalho, ou que não poderá passar a ideia da peça pela moldagem de seu físico.

\section{Algumas Considerações finais}

A resistência de atores de corpos gordos para com a sociedade que os chama de incapazes tem sido totalmente aclamada por críticos e diretores de teatro. Trazer esse assunto para o centro dos holofotes é a melhor forma de conscientizar toda a sociedade de que corpos gordos tem a mesma capacidade e o "ser cênico" do que pessoas com corpos magros, ou consideradas normais pela sociedade. A mudança já é percebida quando observamos que os atores e atrizes gordos já não estão aceitando os papéis que sempre lhes eram colocados pela sociedade gordofóbica. A crescente montagem de peças com esse tema ou que troquem o clássico ator principal magro por atores e atrizes gordos tem sido recorrente.

A tese defendida aqui propõe que no teatro, um corpo é um corpo, sem estereótipos ou marcas corporais. É evidente que as memórias que carregamos irão se manifestar na forma de vermos o mundo, e consequentemente na atuação. As memórias que trazemos vão significar muito na nossa concepção de personagem, mas a imagem gorda não vai alterar a memória visual ou sensorial que temos para a formação na cena que realizaremos.

A imposição de que o corpo gordo pode fazer somente personagens cômicos, ou com baixa autoestima ficará totalmente inadequada se pensarmos nesse sentido. 2019. 


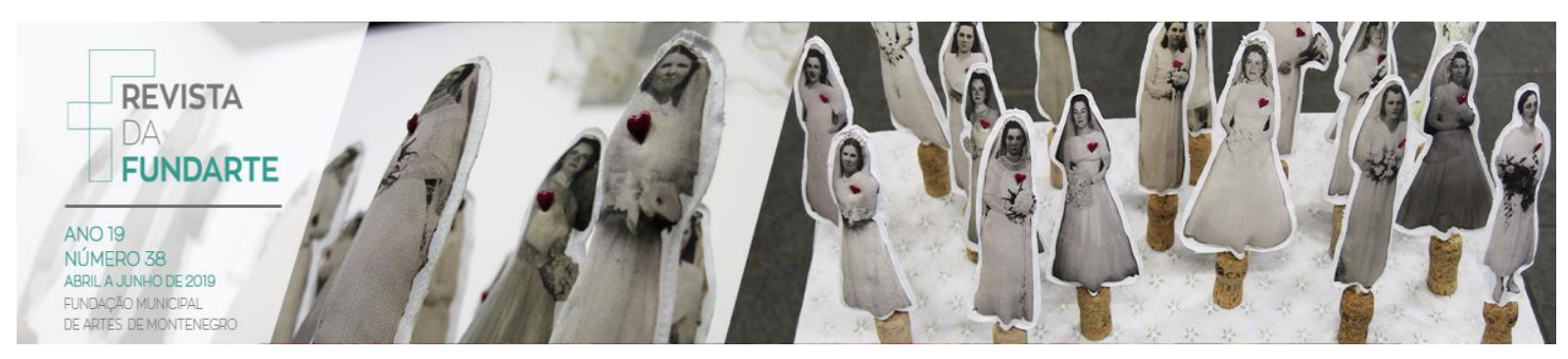

Como estudante de teatro, fazer exercícios passados pelos professores que foram criados por e para pessoas com corpo magro é um desafio, mas é totalmente viável, mesmo sendo criado por homens e mulheres de teatro de séculos passados. O meu limite é onde posso chegar, que qualquer pessoa pode chegar, não necessariamente por ser magra, e sim por ter memórias físicas que me definem, muito mais do que a imagem do meu corpo fora do padrão.

\section{Referências:}

BERGSON, Henri. Matéria e Memória: Ensaio sobre a relação do corpo ao espírito. Brasil: Martins Fontes, 2006.

ROCHA, Taynara. LIMA, Fátima. ARNULF, Stepahn. Ressignificando as banhas: Reflexões sobre o corpo gordo a partir da experiência cênica em SOB Medida. Brasil: UDESC, 2018.

Revista Galileu online, postado em 03/05/2017. Disponível em: https://revistagalileu.globo.com/Revista/noticia/2017/05/gordofobia-por-que-essepreconceito-e-mais-grave-do-que-voce-pensa.html

Brasil Acadêmico on line, postado em 02/08/2015. Disponível em: http://blog.brasilacademico.com/2015/08/personagens-gordos-de-desenhofazem.html

Portal do curso de Jornalismo do Centro Universitário de Mauá, postado em 08/06/2018. Disponível em: https://jornalismo.baraodemaua.br/enc-texto-germanotextosbaraobol-com-br-hoje-2034-voce-de-textosbaraobol-com-br-enviada-2018-0607-211029-para-isgermanoneveshotmail-com-assunto-re-texto-germano-grupo-fala$\underline{\text { sobr/ }}$

FOUCALT, Michel. O corpo utópico, as heterotopias. Brasil: Brochura, 2013. 